\title{
PROPOSAL OF PERFORMANCE ASSESSMENT BY INTEGRATION OF TWO MANAGEMENT TOOLS
}

DOI: 10.12776/QIP.V17I1.143

\section{JAROSLAVA KÁDÁROVÁ, JOZEF MIHOK, RENÁTA TURISOVÁ}

\section{INTRODUCTION}

In a competitive environment, characterized by the scarcity of resources, performance measurement and management assumes a crucial role. Data Envelopment Analysis (DEA) is a non-parametric technique for evaluating the performance of Decision Making Units (DMUs). This method evaluates the efficiency of DMUs in converting multiple inputs into multiple outputs. In recent years,, we have seen the widespread application of DEA in several fields, such as health care, education, manufacturing, retailing, banking, etc. Furthermore, several sophisticated systems for performance assessment have been proposed (Kaplan, 1983).

The Balanced Scorecard (BSC), developed by Kaplan and Norton (Kaplan \& Norton, 1992), is one of the best-known of performance assessment frameworks. Developed from the strategy of the company, this framework includes indicators related to four perspectives: financial, customers, internal processes, learning and growth. Despite the popularity of the DEA and the BSC approach, there have been very few studies that have been interested in their integration for extended performance assessment. In this article, with using a case study from a real company, we have developed four interconnected DEA models, one for each of the BSC perspectives. The use of several complementary models offers richer information for the DMUs.

\section{EFFICIENCY AND DATA ENVELOPMENT ANALYSIS}

Data Envelopment Analysis (DEA) is a relatively new "data oriented" approach for evaluating the performance called Decision Making Units (DMUs) which convert multiple inputs into multiple outputs. Generally, DEA is a nonparametric technique used to measure the efficiency (Cooper et al., 2004).

Efficiency, in the economic sense is defined as: 


$$
\text { Efficiency }=\frac{\text { Output }}{\text { Input }}
$$

Inputs refer to resources such as labour, raw materials and capital. Outputs are items produces from these inputs as a result of the transformation process that occurs within the DMU. "The aforementioned efficiency equation becomes more complicated when the more realistic scenario of measuring multiple inputs and outputs exists." Within this scenario, efficiency must be understood by Popovic $\&$ Martic (2005) as:

$$
\text { Efficiency }=\frac{\text { Weighted sum of Output }}{\text { Weighted sum of Input }}
$$

\section{Environmental factors}

e.g. regulatory- competitive framework, socio- economic background, climate, economic development, functioning of the public administration

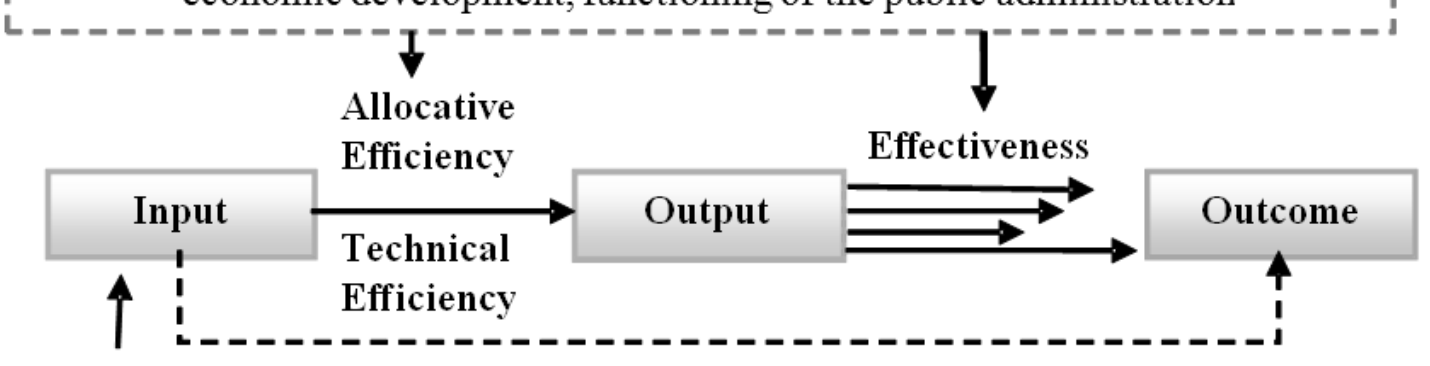

Monetary and non-

monetary resources

Figure 1 - Conceptual framework of efficiency and effectiveness (Mandl, Dierx, Ilzkovitz, 2008)

DEA used to measure technical efficiency. "Technical efficiency looks at the level of inputs or outputs. Being technically efficient means to minimize inputs at a given level of outputs, or maximize outputs at a given level of inputs" (DEA, 2013). The measurement of efficiency in production units and the identification of sources of their inefficiency is a precondition to improve the performance of any productive unit in a competitive environment.

Each DMU is engaged in a transformation process, where by using some inputs (resources) it is trying to produce some outputs (goods or services). DEA uses all the data available to construct a best practice empirical frontier, to which each inefficient DMU is compared. It is called Production Possibility Frontier (PPF). It assumes that all inputs are used efficiently. 


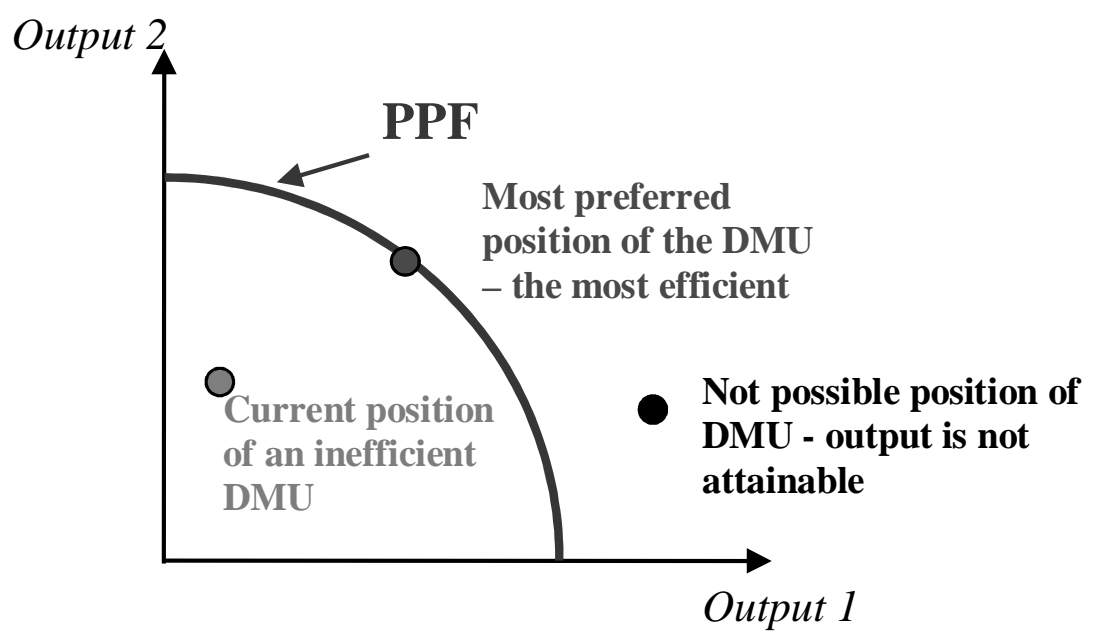

Figure 2 - Illustration of a possible location of the most preferred future position of the DMU

DEA uses the production frontiers to assess relative efficiency. Based on inputs and outputs of the units, DEA forms efficient surfaces. If a DMU lies on the surface, it is efficient; otherwise, it is inefficient.

One of the interesting features of DEA is that it allows each unit to identify a benchmarking group (a group of units that are following the same objectives and priorities, but performing better) (Nasruddin, et al., 2010).

\section{DEA MODEL}

Suppose that we have $n D M U_{s}\left\{D M U_{j}, j=1,2, \ldots, n\right\}$, which produce s outputs $y_{r j}: r=1,2, \ldots . s, j=1,2, \ldots, n$, by consuming $m$ inputs $x_{i j}: i=1,2, \ldots . m, j=1,2, \ldots, n$.

Relative efficiency is defined as the ratio of total weighted outputs to the total weighted inputs.

The $q$-th line - i.e. $x_{i q}$ and $y_{r q}$ - shows quantified inputs/ outputs of unit $D M U_{q}$. The efficiency rate of such a unit can then be generally expressed as (Vincová, 2005):

$$
\theta q=\text { Weighted sum of Outputs/Weighted sum of Inputs }=\frac{\sum_{r=1}^{s} u_{r} y_{r q}}{\sum_{i=1}^{m} v_{i} x_{i q}}
$$

where:

$v_{i}, i=1,2, \ldots, m$, are weights assigned to $i$-th input,

$u_{r}, r=1,2, \ldots, s$, are weights assigned to $r$-th output.

"DEA model derive input and output weights by means of an optimising calculation. Based on that, units can be classified into efficient and inefficient. In inefficient units, they tell us target values of inputs and outputs which would lead 
to efficiency (DEA, 2013). In DEA model, we evaluate $\mathrm{n}$ productive units, $\mathrm{DMU}_{\mathrm{s}}$, where each DMU takes $\mathrm{m}$ different inputs to produce different outputs. The essence of DEA models in measuring the efficiency of productive unit $\mathrm{DMU}_{\mathrm{q}}$ lies in maximising its efficiency rate. However, subject to the condition that the efficiency rate of any other units in the population must not be greater than 1" (Vincová, 2005).

To estimate the DEA efficiency of $D M U_{q}$, we use the following original DEA model (Vincová, 2005):

$$
\text { Maximize } \theta q
$$

Subject to:

$$
\begin{aligned}
& \sum_{j=1}^{n} x_{i j} \lambda_{j} \leq x_{i q} i=1,2, \ldots . m \\
& \sum_{j=1}^{n} y_{r j} \lambda_{j} \geq \theta y_{j q} \quad r=1,2, \ldots . . S \\
& \sum_{j=1}^{n} \lambda_{j}=1 \\
& \lambda_{j} \geq 0 \quad j=1,2, \ldots . n
\end{aligned}
$$

where:

$y_{r q}$ is the amount of output $r$ generated by unit $q$ and $x_{i q}$ is the amount of input $i$ used by unit $q$;

$\lambda_{j}$ is the intensity variable for $D M U_{j}$.

The score $\theta$ obtained from the solution to this linear programming problem is the maximum rate of proportional expansion in all outputs of $D M U_{q}$, without decreasing its inputs. The efficiency rate of $D M U_{q}$ can be obtained by calculating 1/ $\theta$ (Zhu, 2009).

\section{PERFORMANCE AND BALANCED SCORECARD}

The current environment of globalization and economic turbulence has increased the challenges executives face and, therefore, here is the need to find the right tools to meet these challenges with appropriate tools for performance and effectiveness measuring. "In the Slovak Republic conditions for application of new access or knowledge in the cost area and performance area is strong dependent on transformation process of the whole economy" (Rajnoha, Chromjaková, 2009).

Performance measurement is a fundamental principle of management. Like other manufacturing functions, performance measurement is important in managing the maintenance function. Well-defined performance indicators can potentially support identification of performance gaps between current and desired performance and provide indication of progress towards closing the gaps. 
Companies are trying to bridge the gap between strategy and performance of processes with the aim to optimize their performance. Probably the best known, the most sophisticated and in terms of implementation the most successful performance measurement system is called Balanced Scorecard (BSC). It was found to be the sixth most widely used management tools across the globe which also had one of the highest overall satisfaction ratings (according to a multi-year research project launched since 1993 by consulting firm Bain \& Company. In 2011 they received 1230 completed surveys from a broad range of international executives that represent a various industries and company sizes, Figure 3) (Rigby \& Bilodeau, 2011).

The BSC builds a balance between financial and non-financial, organizational and non-organizational performance measures, and hence, suggests a more thorough evaluation methodology.

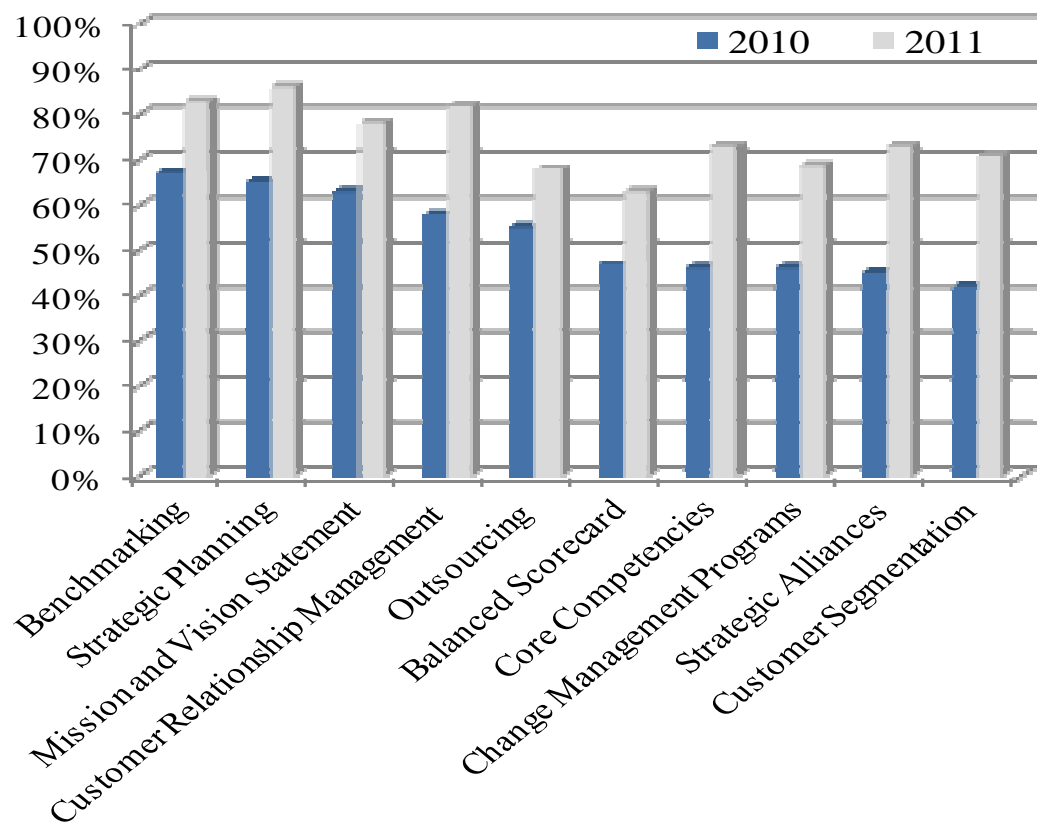

Figure 3 - Expected changes in performance management tools usage (Rigby, Bilodeau, 2011)

It translates a company's strategic objectives into a set of performance measures distributed among four perspectives - financial, customer, internal business processes, and learning and growth (Chytasa, et al., 2011):

\section{- Customer perspective}

"Since companies create value through customers, understanding how they view performance becomes a major aspect of performance measurement"

\section{- Internal business process perspective}

"In the internal business process perspective, executives identify the critical internal processes in which the company must excel". 
- Learning and growth perspective

"This perspective identifies the infrastructure that the company must build to create long-term growth and improvement. Learning and growth come from three principal sources: 1. People; 2. Systems; and 3. Company procedures".

\section{- Financial perspective}

"Within the balanced scorecard, financial measures remain an important dimension. Financial performance measures indicate whether a company's strategy, implementation, and execution are contributing to bottom-line improvement".

For each of the four perspectives, objectives, measures, targets and initiatives are developed as shows BSC model (see Figure 4).

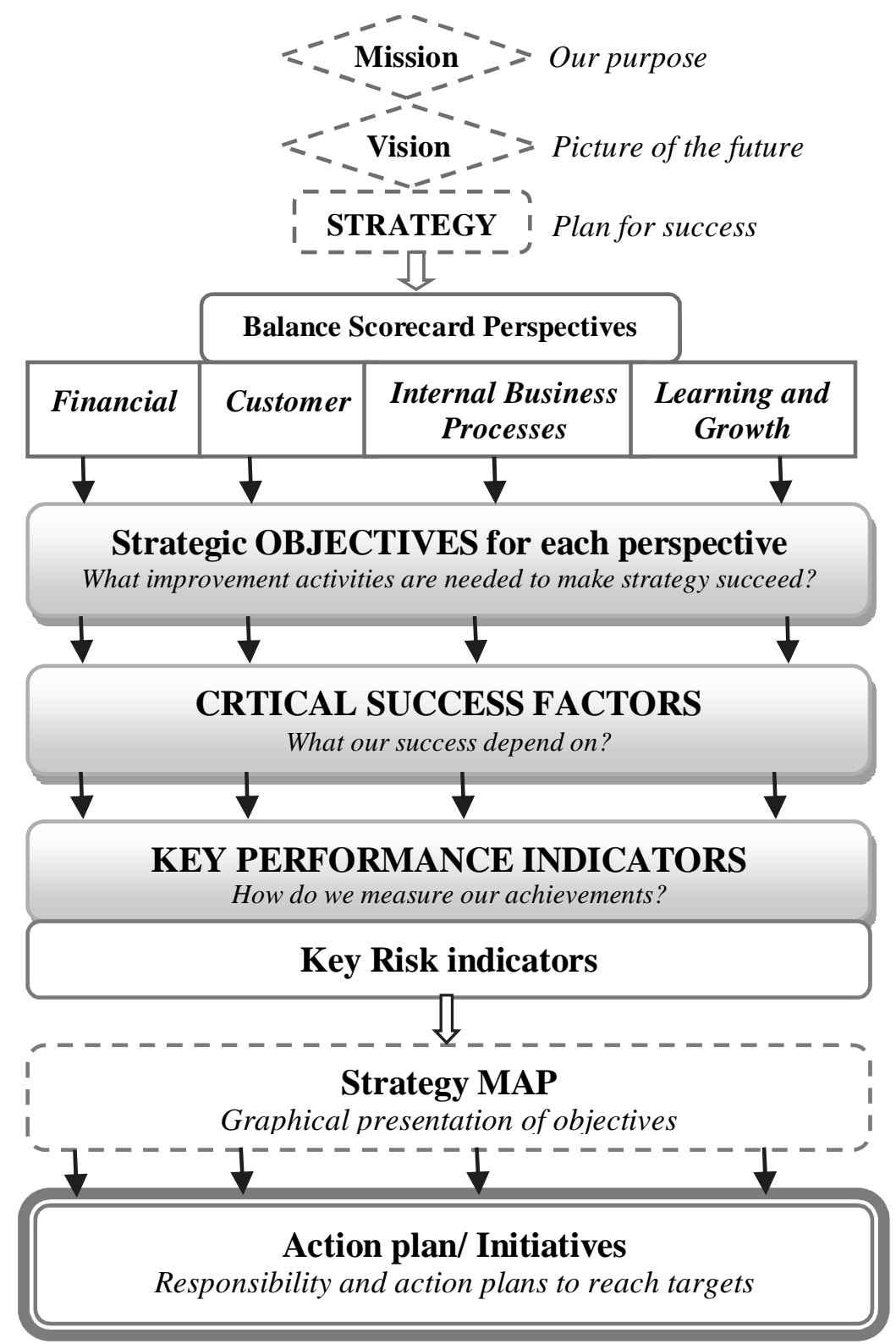

Figure 4 - Model of Balanced Scorecard 


\section{THE INTEGRATION OF DATA ENVELOPMENT ANALYSIS AND BALANCED SCORECARD}

Despite the popularity of the DEA and the BSC approach, there have been very few studies that have explored their integration for enhanced performance assessment. To create a systematic relationship between these two methods we summarize the advantages and disadvantages of both methods in Table 1.

From Table 1 we can find the following facts:

1) DEA has input and output, but BSC has got multi-viewpoint evaluations.

2) In DEA technique, there is no future view, but BSC focuses on future view based on financial perspective which is the result of the past performance and three perspectives of the growth and the learning, the internal processes and the customer.

3) The DEA technique does not apply the strategy of the organization while BSC method uses the strategy of the organization for decision making.

4) It is more difficult to analyze each involving index in BSC while analyzing the DEA results is easier.

Table 1 - Proposed differences between DEA and BSC method (Aryanezhada, et al., 2011)

\begin{tabular}{|l|l|l|}
\hline Compatibility & BSC & DEA \\
\hline Way of comparison & $\begin{array}{l}\text { Comparison with an ideal } \\
\text { virtual unit }\end{array}$ & $\begin{array}{l}\text { Proportional comparison the } \\
\text { same units }\end{array}$ \\
\hline View & Multiple view & Input/ output \\
\hline Mathematical ranking & Weak & Strong \\
\hline Applicable process & $\begin{array}{l}\text { Self assessment of } \\
\text { company }\end{array}$ & Technical efficiency \\
\hline $\begin{array}{l}\text { Accuracy of } \\
\text { measurement }\end{array}$ & Moderate & High \\
\hline $\begin{array}{l}\text { Presenting of } \\
\text { improvement method }\end{array}$ & Moderate & High \\
\hline Ranking & Does not support & Has \\
\hline Future view & Has & Does not have \\
\hline $\begin{array}{l}\text { Regarding to } \\
\text { organization strategy }\end{array}$ & Has & Has \\
\hline
\end{tabular}

As we can observe, an integrated BSC-DEA model could improve the overall capabilities of both models and it could also reduce the faults of each one. 


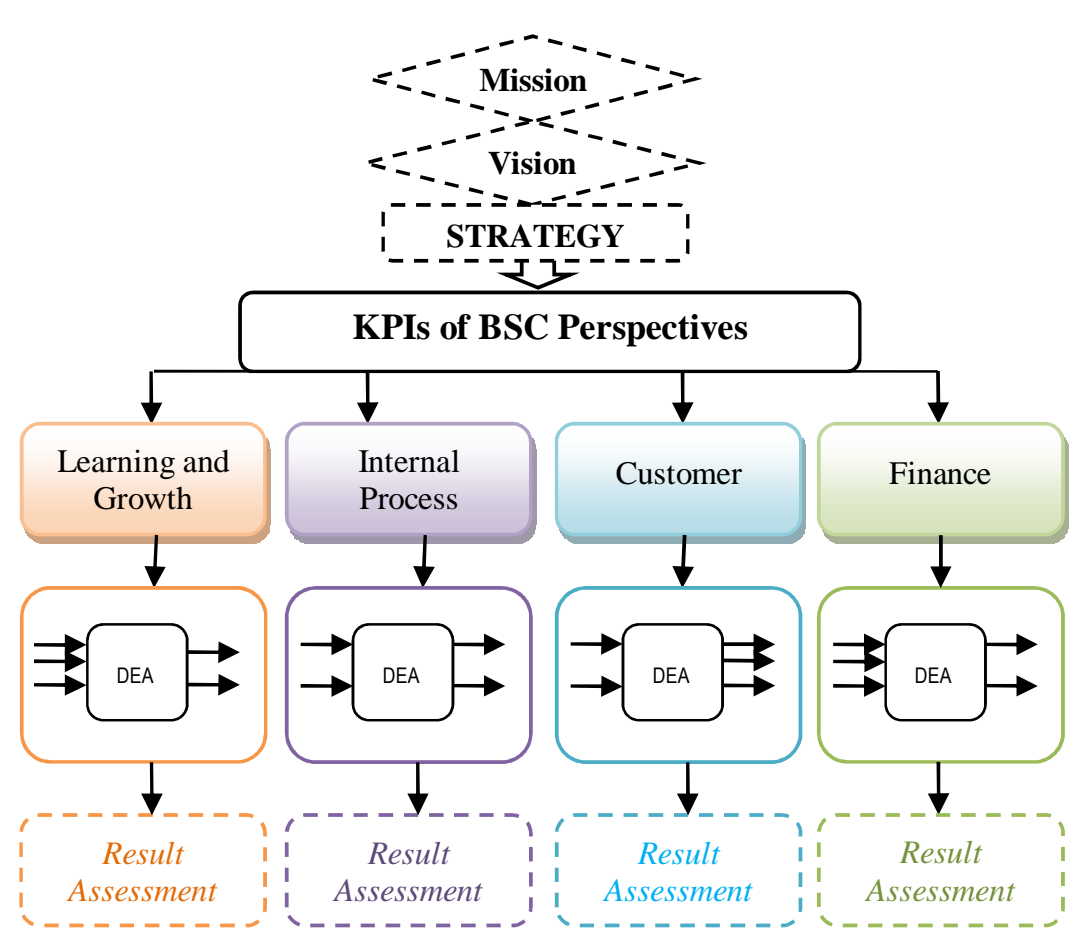

Figure 5 - Proposed integrated model of DEA and BSC (Aryanezhada, Najafib, Farkousha, 2011)

Figure 5 shows the details of the proposed DEA-BSC model, which includes four major strategies of learning and growth, internal process, customer and finance. This process needs to be executed continuously to help company reach its goals. The input and the output parameters for the DEA are values of selected key KPIs (Aryanezhada et al., 2011). In the next section we describe the empirical analysis undertaken with a case study.

\section{INTEGRATION OF DEA WITH THE BSC - CASE STUDY}

In order to develop the DEA models to assess the performance of the Maintenance Departments from multiple perspectives, first, it is necessary to develop a simplified BSC model for the studied company, which was founded in 2003. Since then team of engineers have been gathering experiences from various fields of mechanical engineering. It offers a wide range of road maintenance equipment. 


\section{VISION}

To be recognized by our customers as a leading company in service excellence, capable of offering unique solutions, with high standards of safety, comfort, dependability and technology.

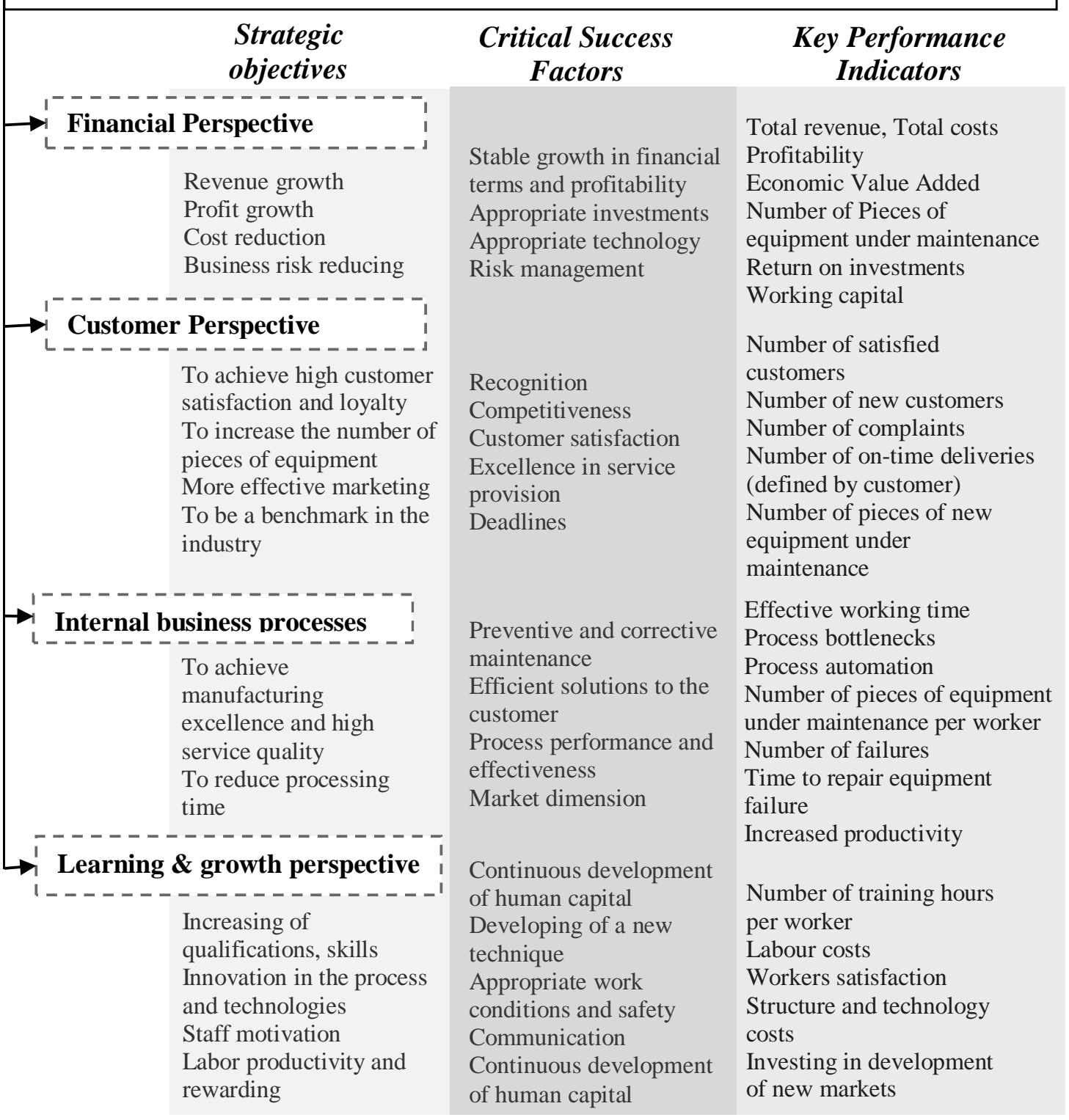

\section{Figure 6-BSC model for the studies company}

Several workshops were undertaken with the heads of department and other managers in order to identify strategic objectives, critical success factors and key performance indicators. Considering that the BSC tells how each part of the company contributes to its success, by following a series of explicit cause and effect relationships, we believe that it can offer a useful framework to structure several interconnected DEA models (Kaplan \& Norton, 1996). 


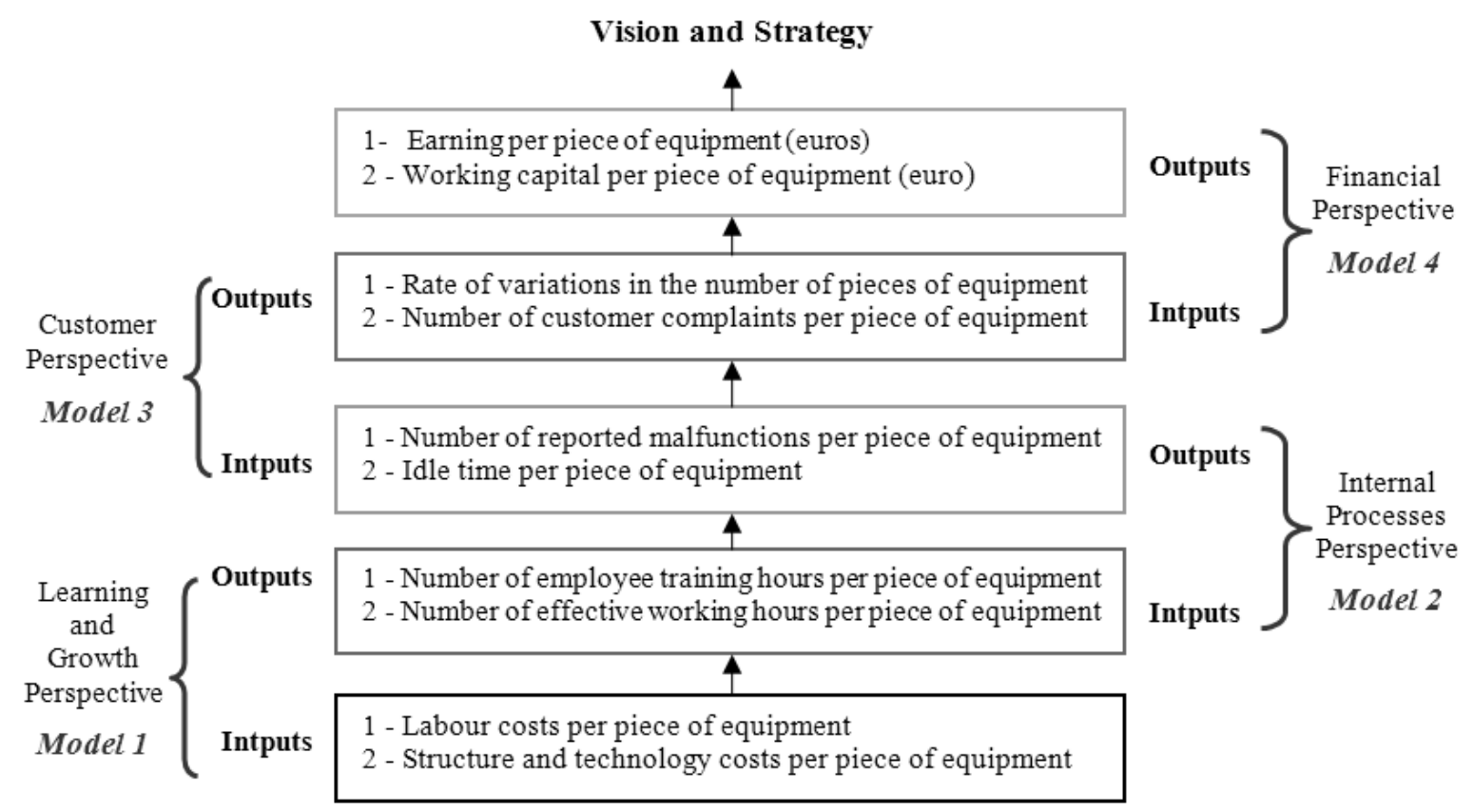

Figure 7 - Proposed four DEA models for particular BSC perspectives based on KPIs of Maintenance Department (Amado, et al., 2012)

An analysis of the results of these models can offer rich information which the company can follow to improve its overall performance. By using the outputs of one model as inputs for the following model, we assume that the transformation of initial inputs into final outputs can be decomposed into several stages characterized by the production of several intermediate outputs. Our goal is to show that the integration of these two methods can offer critical information and shed some light into the needed actions of decision-makers. By doing so, we are able to identify opportunities to help five Maintenance Departments (our DMUs) to improve its performance, which would likely be missed by using a single DEA model embracing the four perspectives of the BSC (Amado, et al., 2012).

For our analyze we use Konsi software product for supporting marketing analysis and financial planning, which is based on the DEA framework (Dea Applications).

First we imported data from the file (prepared Excel document) and defined List of parameters - our selected Key performance indicators for DEA models (see Figure 8). 


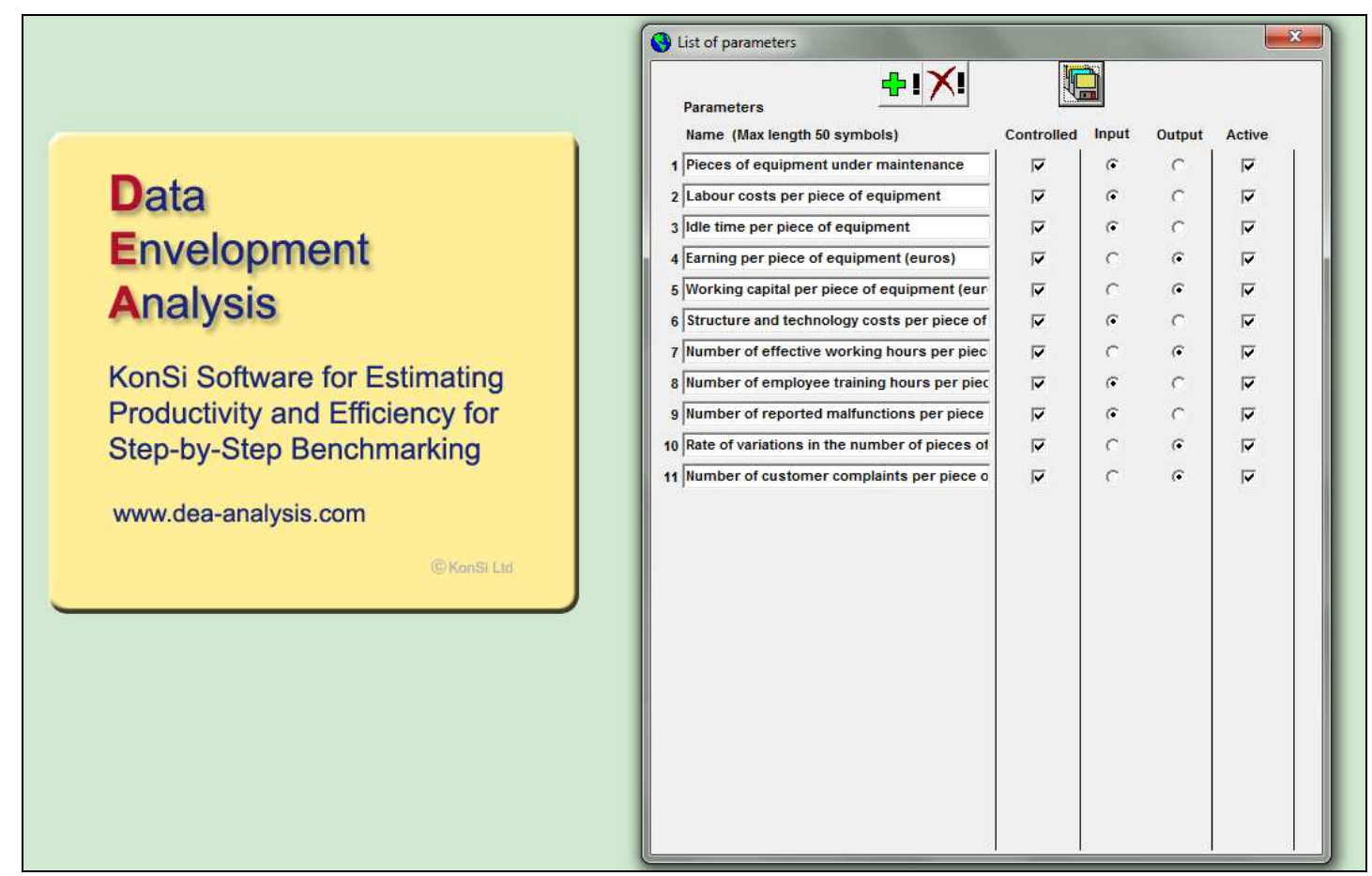

Figure 8-List of parameters

Table 2 presents the descriptive statistics for the variables used in the four DEA models for the five DMUs (Maintenance Departments) relative to the year 2011.

Table 2 - Prepared data from Excel document

\begin{tabular}{|c|c|c|c|c|c|c|c|c|c|c|c|}
\hline & 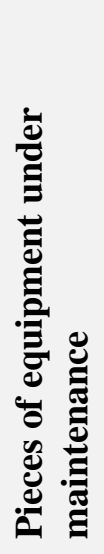 & 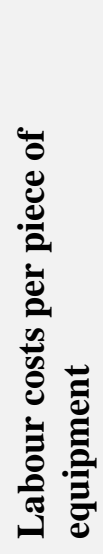 & 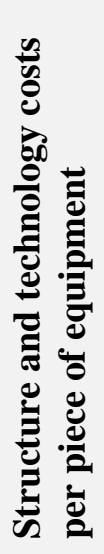 & 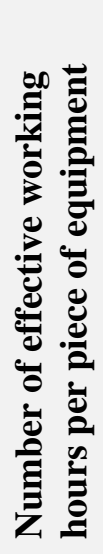 & 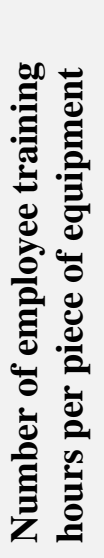 & 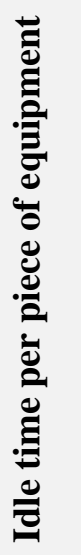 & 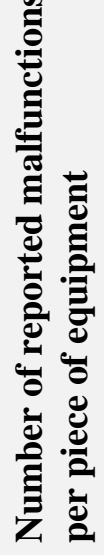 & 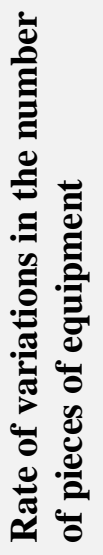 & 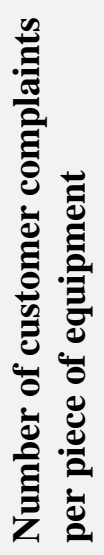 & 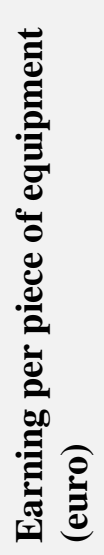 & 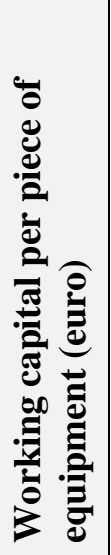 \\
\hline DMU1 & 2498 & 309 & 152 & 41 & 0,5 & 12 & 2 & 0,02 & 0,01 & 742 & 850 \\
\hline DMU2 & 2548 & 313 & 153 & 43 & 0,75 & 10 & 2,5 & 0,03 & 0,01 & 750 & 865 \\
\hline DMU3 & 1995 & 299 & 158 & 39 & 0,5 & 12 & 3 & 0,02 & 0,02 & 755 & 870 \\
\hline DMU4 & 2116 & 303 & 148 & 41 & 0,5 & 11 & 2 & 0,03 & 0,01 & 736 & 845 \\
\hline DMU5 & 2798 & 332 & 150 & 42 & 0,75 & 10 & 1,5 & 0,02 & 0,01 & 720 & 830 \\
\hline Average & 2391 & 311,2 & 152,2 & 41,2 & 0,6 & 11 & 2,2 & $\mathbf{0 , 0 2}$ & 0,01 & 740,6 & 852 \\
\hline
\end{tabular}


In the List of Parameters we can define the parameter as controlled, output, input or active. The four DEA models presented in Figure 8, with output-orientation, were processed by the KonSi software, in order to obtain relative performance scores for each of the five compared DMUs.

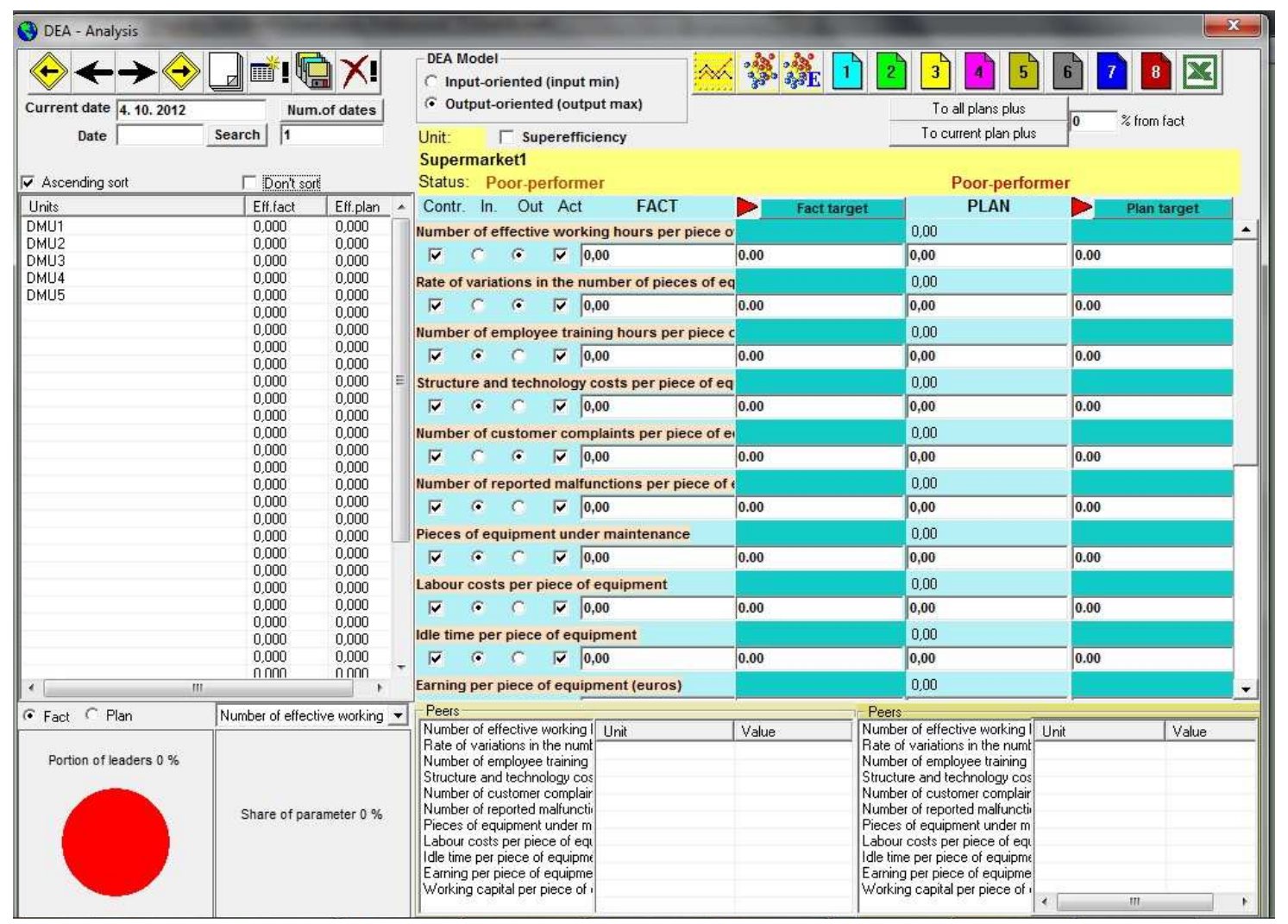

Figure $9-D E A$ analysis

Table 3 presents the performance scores obtained for the various Maintenance Departments based on the output - oriented models.

Table 3 - Performance scores for the particular Maintenance Departments

\begin{tabular}{|c|c|c|c|c|}
\cline { 2 - 5 } \multicolumn{1}{c|}{} & \multicolumn{4}{c|}{ BSC Perspectives } \\
\cline { 2 - 5 } & $\begin{array}{c}\text { Learning \& } \\
\text { growth (\%) }\end{array}$ & $\begin{array}{c}\text { Internal } \\
\text { Processes (\%) }\end{array}$ & Customer (\%) & Financial (\%) \\
\hline DMU1 & 77 & 82 & 73 & 94 \\
\hline DMU2 & 91 & 86 & 84 & 86 \\
\hline DMU3 & 84 & 81 & 85 & 80 \\
\hline DMU4 & 100 & 91 & 86 & 100 \\
\hline DMU5 & 100 & 93 & 94 & 82 \\
\hline Average & $\mathbf{9 0 , 4}$ & $\mathbf{8 6 , 6}$ & $\mathbf{8 4 , 4}$ & $\mathbf{8 8 , 4}$ \\
\hline
\end{tabular}


As can be seen from table above, the results reveal that, in global terms, the perspective of internal processes requires special attention, with an average score of $86,6 \%$. The learning and growth perspective presents high levels of performance, with an average score $90,4 \%$.

\section{CONCLUSION}

This paper presented an integration of two the most popular methods used for company performance and effectiveness evaluation: the DEA and the BSC. Moving away from a unique all-embracing DEA or BSC models towards multiple complementary models is advantageous, leading to increased performance assessment. In a case study of a multinational company operating in the business of vertical transportation, we developed four DEA models, one for each one of the BSC perspectives.

\section{AKNOWLEDGEMENT}

This contribution is the result of the project implementation: Centre for research of control of technical, environmental and human risks for permanent development of production and products in mechanical engineering (ITMS: 26220120060) supported by the Research \& Development Operational Program funded by the ERDF and project VEGA 1/0669/13 Proactive crisis management of industrial enterprises based on the concept of controlling.

\section{REFERENCES}

Amado, C., Santos, S. P., Marques, P. M., 2012. Integrating the Data Envelopment Analysis and the Balanced Scorecard approaches for enhanced performance assessment, in Omega, No. 40, pp. 390-403. DOI:10.1016/j.omega.2011.06.006.

Aryanezhad, M. B., Najafi, E., Farkoush, S. B., 2011. A BSC-DEA approach to measure the relative efficiency of service industry: A case study of banking sector, In International Journal of Industrial Engineering Computations No. 2, pp. 273-282. DOI: 10.5267/j.ijiec.2010.03.004.

Chytasa, P., Glykasb, M. and Valiris, G., 2011. A proactive balanced scorecard, In International Journal of Information Management, No. 31, pp. 460- 468. DOI: 10.1016/j.ijinfomgt.2010.12.007.

Cooper, W. W., Seiford, L. M. and Zhu, J., 2004. Data Envelopment Analysis: History, Models and Interpretations, In Handbook on Data Envelopment Analysis, Kluwer Academic Publisher, Boston, Chapter 1, pp. 1-39. 
DEA 2013. DEA Applications for measuring Efficiency: software "KonSi DEA Analysis". Available from: <http://www.dea-analysis.com/> [Accessed 15 February 2013].

Kaplan, R. S., 1983. Measuring manufacturing performance: a new challenge for managerial accounting research, The Accounting Review, Vol. 58, No. 4, pp. 686-705. Available from: 〈http://www.jstor.org/stable/247063> [Accessed 2 February 2013].

Kaplan, R. S. and Norton, D. P., 1992. The Balanced Scorecard-Measures that drive performance, Harvard Business Review.

Kaplan, R. S. and Norton, D. P., 1996. The Balanced Scorecard - translating strategy into action, Harvard Business Review Press.

Mandl, U., Dierx, A. and Ilzkovitz, F., 2008. The effectiveness and efficiency of public spending, In Economic Papers, pp. 3. Available from: $\langle$ http://ec.europa.eu/economy_finance/publications/publication11902_en.pdf > [Accessed 2 March 2013].

Nasruddin, H., Mariam, M. T. and Parvaneh, S., 2010. Resolving Multi objectives Resource Allocation Problem Based on Inputs and Outputs Using Data Envelopment Analysis Method. In Australian Journal of Basic and Applied Sciences, Vol. 10, No. 4, ISSN 1991-8178, pp. 5320-5325.

Popovic, G. and Martic, M., 2005. Two- stage DEA use for assessing efficiency and effectiveness of micro-loan program, in Proceedings of: The 7th Balkan Conference on Operational Research, BACOR 05, Constanta, Romania, May $2005 . \quad$ Available from: <http://fmi.unibuc.ro/balkanconf/CD/Section6/popovic_martic.pdf > [Accessed 2 February 2013] .

Rajnoha, R. and Chromjaková, F., 2009. Activity based costing and efficiency of its application in the wooden houses production, in Drewno, Vol. 52, No. 181, ISSN 1644-3985, pp. 105-128.

Rigby, D. and Bilodeau, B., 2011. Management Tools and Trends, Available from:

$<$ http://www.loyaltyrules.com/management_tools/Management_Tools_and_Tren ds_2011_Final_Results.pdf> [Accessed 2 March 2012].

Vincová, K. 2005. Using DEA models to measure efficiency, in BIATEC, Vol. XIII, No. 8/2005, pp. 24-28.

Zhu, J., 2009. Quantitative Models for Performance Evaluation and Benchmarking: Data Envelopment Analysis with Spreadsheets, Springer Science +Business Media, LLC. 


\section{ABOUT THE AUTHORS}

doc. Ing. Jaroslava Kádárová, PhD., Technical University of Košice, Faculty of Mechanical Engineering, Department of Industrial Engineering and Management, Němcovej 32, 04200 Košice, Slovak Republic, e-mail: jaroslava.kadarova@tuke.sk.

Dr. h. c. mult. prof. Ing. Jozef Mihok, PhD., Technical University of Košice, Faculty of Mechanical Engineering, Department of Industrial Engineering and Management, Němcovej 32, 04200 Košice, Slovak Republic, e-mail: jozef.mihok@tuke.sk.

Ing. Renáta Turisová, PhD., Technical University of Košice, Faculty of Mechanical Engineering, Department of Industrial Engineering and Management, Němcovej 32, 04200 Košice, Slovak Republic, e-mail: renata.turisova@tuke.sk. 